\title{
EVALUATION OF THE EFFECT OF INADAPTABLE RISK FACTORS \& SOCIAL STATUS ON DIABETIC FOOT ULCER
}

\author{
Saniya Khalique \\ Department of Physiology, University of Karachi \\ Corresponding Author Email: saniya811@hotmail.com
}

\begin{abstract}
Diabetic Foot Ulcer subjects (DFUS) were clinically examined in the urban areas of Karachi. Neuropathy, peripheral vascular disease, foot deformity, improperly fitted shoes can make a diabetic person at risk of foot ulcer. In the present study, prevalence, role of inadaptable risk factors (age, gender, height) and socio-economic status were examined in DFUS and normal diabetic patients (NDP) taken as control. A total of randomly selected subjects $\mathrm{N}=59$; male $=33$, female $=26$ (DFUS: $\mathrm{n}=41$; male $=22$, female $=19$; NDP: $\mathrm{n}=18$; male $=11$, female $=7$ ). In this study prevalence of DFU was found in male gender as $54 \%$ of our patients were male and $46 \%$ were female. Mean \pm S.E.M. of male DFUS height was $5.7 \pm 0.353 \mathrm{ft}$ while that of women was $5 \pm 0.306 \mathrm{ft}$, this greater height in male makes them predominant for DFU. Mean \pm S.E.M. of age for DFUS males: $58 \pm 10.237$ years, that is comparatively higher than control NDP males: $56.81 \pm 10.235$ years. Mean \pm S.E.M. of age for DFUS females: $54 \pm 11.18$ years which is also significantly higher than control NDP females: $49.57 \pm$ 9.727 years. The greater part of the investigated patients belonged to lower class ( $54 \%$ males \& $74 \%$ of females).
\end{abstract}

\section{KEYWORDS}

Diabetic Foot Ulcer subjects, neuropathy, socio-economic status, prevalence, age, height, normal diabetic patients.

\section{INTRODUCTION}

The triad of neuropathy, deformity, and trauma is present in almost two-thirds or patients with foot ulcers (Boulton, 2004; Rivner, 2001). Ill-fitting shoes are a common mechanism for the pathogenesis of foot ulcerations and pain. (Most, 1983; Reddy, 1989). When diabetic patients also have peripheral arterial disease, their capillaries become fragile. Fragile capillaries can be subject to micro-hemorrhages, which could be the reason that infection spreads through the tissues (Lavery, 2008). It was abundantly apparent that the actual cause of the perforating ulcer was peripheral nerve degeneration and that diabetes itself played an active part in the causation of the perforating ulcer (Younger, 1998; Zacur, 2002). Infection of the foot in diabetic patients presents a severe threat to the affected limb and should be evaluated and treated without delay (Armstrong 1998; Sorensen, 2002). Infection is diagnosed by the presence of signs and symptoms of inflammation, but these may be blunted by neuropathy or ischemia, and systemic findings (e.g. fever, increased white blood count) are often absent (Pecoraro, 1990). Infections should be classified as mild (superficial with nominal cellulitis), moderate (deeper or more extensive), or severe (accompanied by systemic signs of sepsis). If not properly treated, infection can spread to underlying tissues, including the bone. Mild (superficial and limited) infection is usually caused by aerobic Gram-positive cocci, especially Staphylococcus aureus. Chronic infections and infections that are more severe are often polymicrobial with aerobic Gram-negative rods and anaerobes (Bakker, 2012).

Different types of infections occurring in DFUS like superficial infections occupy tissue layers above the superficial fascia and present in the form of acute bacterial cellulitis. Deep infections occupy the superficial fascia, muscles or bones and joints. Cellulitis is a bacterial infection of the subdermis (Reiber, 1999). Necrosis occurring as necrotizing cellulitis which is characterized by tissue necrosis of the sub dermis and then dermis. Necrotizing fasciitis corresponds to involvement of the superficial fascia, presenting in the form of sloughing of the skin and a violaceous color of the integument without pus or abscess. Rapid deterioration of the general status, development of renal failure, sudden extension of the lesions, cutaneous sensory loss and the presence of skin detachment constitute warning signs of necrotizing fasciitis. Regarding the prevalence foot complications are exceedingly common with an estimation that more than $5 \%$ of diabetic patients will have a history of foot ulcers whilst the increasing lifetime risk of foot ulceration may be as high as $25 \%$ (Singh, 2005; Steed, 2008). While in Pakistan there will be an estimated 248000 new DFU patients each year and estimated national annual cost of ulcer management is 6.9 billion rupees (50 million pounds) (Ali, 2008). The aim of present study is to examine the role of prevalence, inadaptable risk factors (age, gender, and height) and socio-economic status in the incidence of DFU.

\section{MATERIAL AND METHODS}

Subjects:

A total of $\mathrm{N}=59$ diabetic patients were selected to participate in the study. Male and female both are include, having ages between 35 81years.

\section{Clinical protocol:}

The research was carried out in urban regions of Karachi (Pakistan). A questionnaire comprising queries concerning demographic details, preventive measure scale, associated symptoms, managements and family history of DFU was filled voluntarily by the patients. Physical measurements of the subjects like B.P, weight, height were also done during study. The test reports assessed in the study includes; complete blood test report, blood glucose level ( $\mathrm{mg} / \mathrm{dl})$, Hb level $(\mathrm{g} / \mathrm{dl})$, blood group and a list 
of prescribed drugs/pills were also taken into consideration. In this study we took into account the "International Consensus on the Diabetic Foot classification of foot wound infections" in order to divide the subjects into 4 different grades. Grade 1 having no symptoms was taken as control. Total controls were $n=18$ out of which $n=11$ were male and $n=7$ were female. While subjects placed in grade 2-4 were the DFU patients, categorized according to their level of symptoms severity. Total patients were $n=41$, out of which $n=22$ were male and $n=19$ were female.

\section{Statistical analysis:}

The data expressed as mean \pm S.E.M. and percentage. P-values were also evaluated.

\section{RESULTS}

\section{Prevalence \& role of inadaptable risk factors}

In our study almost $54 \%$ of patients were male, while $46 \%$ were female (Table 2). In our study the ages of male subjects were between 44-81 years. The mean age of male control subjects was $56.81 \pm 10.235$ ( $\mathrm{p}$ value $>0.05$ ), while that of patients was $58 \pm$ 10.237 ( $\mathrm{p}$ value $>0.05$ ). On the contrary the ages of female subjects were between 35-74 years. The mean age of female control subjects was $49.57 \pm 9.727$ ( $\mathrm{p}$ value $>0.05$ ), while that of patients was $54 \pm 11.18$ ( $\mathrm{p}$ value $>0.05$ ). In our study the mean height of male patients was $5.7 \pm 0.353$ ( $\mathrm{p}$ value $<0.05$ ), while of control was $6 \pm 0.326$ ( $\mathrm{p}$ value $<0.05$ ). On the contrary the mean height of female patients was $5 \pm 0.306$ ( $p$ value $<0.05$ ), while of control was $5 \pm 0.208$ ( $\mathrm{p}$ value $<0.05$ ), which is relatively less (Table 1).

\begin{tabular}{|c|c|c|c|c|c|c|}
\hline \multirow[t]{3}{*}{ PARAMETERS } & \multicolumn{5}{|c|}{ CLINICAL GROUPS } & \\
\hline & \multicolumn{3}{|c|}{ DFUS } & \multicolumn{3}{|c|}{ NDP } \\
\hline & MALES & FEMALES & $p$ value $=0.05$ & MALES & FEMALES & $p$ value $=0.05$ \\
\hline Age (yr) & $58 \pm 10.237$ & $54 \pm 11.18$ & 0.18976224 & $56.81 \pm 10.235$ & $49.57 \pm 9.727$ & 0.15427752 \\
\hline Height (ft) & $5.7 \pm 0.353$ & $5 \pm 0.306$ & $1.07 \mathrm{E}-06$ & $6 \pm 0.326$ & $5 \pm 0.208$ & $8.93 \mathrm{E}-05$ \\
\hline
\end{tabular}

Table 1: Clinical examination of age and height of males and females in DFUS AND NDP

\section{Socio-economic status:}

In our study $54 \%$ of male patients were from lower class, $9 \%$ from lower middle and $36 \%$ were from middle class. On the contrary $82 \%$ of control males were from middle class and $9 \%$ (each) were from lower and lower middle class. While in female $74 \%$ were from lower class and $26 \%$ were from middle class. Relatively in control female $71 \%$ had middle status and $29 \%$ were from lower middle class (Table 2).

\begin{tabular}{|l|c|c|c|c|}
\hline PARAMETERS & \multicolumn{4}{|c|}{ CLINICAL GROUPS } \\
\hline & MALES & FEMALES & MALES & FEMALES \\
\hline Gender & $54 \%$ & $46 \%$ & $61 \%$ & $39 \%$ \\
\hline $\begin{array}{l}\text { Socio-economic status } \\
\text { (Lower) }\end{array}$ & $54 \%$ & $74 \%$ & $9 \%$ & - \\
\hline
\end{tabular}

Table 2: Clinical examination of gender prevalence and social status of males and females in DFUS and NDP

\section{DISCUSSION}

According to a study consistently higher ulcer rate was found in males than in females (Preston, 1993). Another study found that men with diabetes have almost twice the chances of having insensate neuropathy as women with diabetes. The reason is that they have nerve conduction abnormalities that are more severe. Differences in biomechanics between men and women, purposely, decreased joint mobility and higher foot pressures, may predict the development of diabetic foot ulcers. According to a 2008 study, male patients had less joint mobility and higher foot pressures than females. So they are more likely of becoming a victim of foot ulcer. The study also found that women had parallel odds as men of diabetes linked foot ulcers developing if the women had the same measures of neuropathy, joint mobility, and foot pressures as the male patients (McKee, 2010). One study indicates that the estimated amputation rate in diabetic subjects is higher for males than for females. This was a uniform finding in most U.S. hospital discharge studies, with 1.4-2.7 times excess risk for males compared with females (Most, 1983). In 1990, the age-adjusted amputation rate for diabetes, computed from some data, was $61 \%$ higher in males than females.

Age plays a vital role in developing DFU. According to a study age is also a risk factor for foot ulcers and amputations (Sämann, 2008). A study said that the highest rates of DFU were observed in individual's age 45-64 years (Preston, 1993). Another study said that diabetics over 65 years are more at risk of foot ulcers (Lavery, 2008). Although it is now recognized that Type 2 Diabetes Mellitus in children is becoming a universal public health issue. So 
it is quite inevitable that these young people will go on to develop diabetes-related macrovascular complications, including disabling and life-threatening foot problems, at a comparatively early age (Van Houtum, 2005). The possible reason of older age diabetic patients more susceptible to ulcers could be because of decreased angiogenesis and increased sepsis. Additionally they have physiological impairment to healing (Brem, 2001). According to one study the estimated amputation rate was 1.4 and 2.4 times higher for individuals age 65-74 years and age 75 years, respectively, compared with those age 0-64 years. In our study the mean age of male control subjects was $56.81 \pm 10.235$ ( $\mathrm{p}$ value > 0.05 , which is significant), while that of patients was $58 \pm 10.237$ ( $\mathrm{p}$ value $>0.05$, which is significant). On the contrary the ages of female subjects were between 35-74 years. The mean age of female control subjects was $49.57 \pm 9.727$ ( $\mathrm{p}$ value $>0.05$, which is significant), while that of patients was $54 \pm 11.18$ (p value > 0.05 , which is significant) (Table 1).

Increased height gives a connection with neuropathy leading to foot ulcer in diabetics. A researcher said that a possible reason for increased insensate neuropathy among men may be related to greater height in men. Insensate neuropathy is partly determined by peripheral nerve length, which is a function of height. Another study found that the effect of height was entirely responsible for increased odds of sensory neuropathy in men (McKee, 2010). Height is an imperative and a practical analyst of peripheral insensate neuropathy. As the height amplify, the span of the nerve fibers also increase and so the surface area of the axons is available for the toxin exposure and the physical damage is more. So, the threat of peripheral insensate neuropathy increases with an increase in height. Many studies have shown the link of height with peripheral neuropathy and amputation among diabetics which eventually leads to foot ulcers (Sorensen., 2002; Herman, 2005). Although it is still unknown whether there is any threshold in association between height and the risk for peripheral insensate neuropathy in the common populace. In some studies it is shown that sural conduction velocity decreases with age and height (Rivner, 2001; Stetson, 1992). In our study the mean height of male patients was $5.7 \pm 0.353$ ( $\mathrm{p}$ value $<0.05$, non-significant), while of control was $6 \pm 0.326$ ( $\mathrm{p}$ value $<0.05$, non-significant). On the contrary the mean height of female patients was $5 \pm 0.306$ ( $\mathrm{p}$ value $<0.05$, non-significant), while of control was $5 \pm 0.208$ (p value $<0.05$, non-significant), which is relatively less (Table 1 ).

Socioeconomic status is a term that attempts to capture an individual's capacity to function within society. This is often measured using their level of education, annual income, or community of residence. Several studies support the proposal that lower socioeconomic status bears a higher possibility of amputation. This impacts the overall health of an individual in many ways. Lower education can decrease an individual's health literacy, the understanding of one's health, and behaviors that promote a healthy lifestyle. It may also impair early recognition of pathology before it becomes limb threatening. Annual income may effect the means to seek or get care or purchase medications to carry out treatments prescribed by the medical team. Lower income may also reflect an occupation that does not allow the absence from work in order to seek care (Resnick, 2004; Resnick, 1999; Rockville, 2010). Despite all these facts it is not impractical to find DFU patients in other socio-economic statuses. In our study $54 \%$ of male patients were from lower class, $9 \%$ from lower middle and $36 \%$ were from middle class. On the contrary $82 \%$ of control males were from middle class and $9 \%$ (each) were from lower and lower middle class. While in female $74 \%$ were from lower class and $26 \%$ were from middle class. Relatively in control female $71 \%$ had middle status and $29 \%$ were from lower middle class (Table 2).

\section{REFERENCES}

- $\quad$ Ali, S. M., Fareed, A., Humail, S. M., Basit, A., Ahmedani, M. Y., Fawwad, A., \& Miyan, Z. (2008). The personal cost of diabetic foot disease in the developing world-a study from Pakistan. Diabetic Medicine, 25(10), 1231-1233

- Armstrong, D. G., \& Lavery, L. A. (1998). Diabetic foot ulcers: prevention, diagnosis and classification. American family physician, 57(6), 1325-32.

- $\quad$ Bakker, K., Apelqvist, J., \& Schaper, N. C. (2012). Practical guidelines on the management and prevention of the diabetic foot 2011. Diabetes/metabolism research and reviews, 28(S1), 225-231.

- Boulton, A. J., Kirsner, R. S., \& Vileikyte, L. (2004). Neuropathic diabetic foot ulcers. New England Journal of Medicine, 351(1), 48-55.

- Brem, H., Tomic-Canic, M., Tarnovskaya, A., Ehrlich, H. P., Baskin-Bey, E., Gill, K., \& Vladeck, B. (2001). Healing of elderly patients with diabetic foot ulcers, venous stasis ulcers, and pressure ulcers. Surgical technology international, 11, 161-167.

- Herman, W. H., \& Kennedy, L. (2005). Underdiagnosis of peripheral neuropathy in type 2 diabetes. Diabetes care, 28(6), 1480-1481.

- Lavery, L. A., Baranoski, S., \& Ayello, E. A. (2008). Diabetic foot ulcers.Wound Care Essentials and Practice Principles. 2nd ed. Philadelphia, PA: Lippincott Williams Wilkins, 338-362.

- McKee, J. (2014). Examining differences in diabetic foot amputation. American academy of ortheopaedic surgeons, 8(11).

- $\quad$ Pecoraro, R. E., Reiber, G. E., \& Burgess, E. M. (1990). Pathways to diabetic limb amputation: basis for prevention. Diabetes care, 13(5), 513-521.

- $\quad$ Preston, S.D., Reiber, G.E., Koepsell, T.D. (1993). Lower extremity amputations and inpatient mortality in hospitalized persons with diabetes: National population risk factors and associations. University of Washington Thesis.

- $\quad$ Reddy, P. V., Vaid, M. A., \& Child, D. F. (1989). Diabetes and incorrectly fitting shoes. Practical Diabetes International, 6(1), 16-16.

- $\quad$ Reiber, G. E., Vileikyte, L. O. R. E. T. T. A., Boyko, E. D., del Aguila, M. I. C. H. A. E. L., Smith, D. G., Lavery, L. A., \& Boulton, A. J. (1999). Causal pathways for incident lowerextremity ulcers in patients with diabetes from two settings. Diabetes care, 22(1), 157-162.

- $\quad$ Resnick, H.E., Carter, E.A., Sosenko, J.M., et al. (2004). Incidence of lower-extremity amputation in American Indians: the Strong Heart Study. Diabetes Care, 27( ), 188591.

- $\quad$ Resnick, H.E., Valsania, P., Phillips, C.L. (1999). Diabetes mellitus and nontraumatic lower extremity amputation in black and white Americans: the National Health and 
Nutrition Examination Survey Epidemiologic Follow-up Study (1971-1992). Archives of internal medicine, 159(20), 2470-2475.

- $\quad$ Rivner, M. H., Swift, T. R., \& Malik, K. (2001). Influence of age and height on nerve conduction. Muscle \& nerve, 24(9), 1134-1141.

- Sämann, A., Tajiyeva, O., Müller, N., Tschauner, T., Hoyer, H., Wolf, G., \& Müller, U. A. (2008). Prevalence of the diabetic foot syndrome at the primary care level in Germany: a cross-sectional study. Diabetic Medicine, 25(5), 557-563.

- Singh, N., Armstrong, D. G., \& Lipsky, B. A. (2005). Preventing foot ulcers in patients with diabetes. Jama, 293(2), 217-228.

- $\quad$ Sorensen, L., Molyneaux, L., \& Yue, D. K. (2002). Insensate versus painful diabetic neuropathy: the effects of height, gender, ethnicity and glycemic control. Diabetes research and clinical practice, 57(1), 45-51.

- $\quad$ Stetson, D. S., Albers, J. W., Silverstein, B. A., \& Wolfe, R. A. (1992). Effects of age, sex, and anthropometric factors on nerve conduction measures. Muscle \& nerve, 15(10), 1095 1104.

- Van Houtum, W. H. (2005). Barriers to the delivery of diabetic foot care. The Lancet, 366(9498), 1678-1679.

- $\quad$ Younger, D. S. (1998). Diabetic peripheral neuropathy. Drug Today, 34, 699.

- Zacur, H., \& Kirsner, R. S. (2002). Debridement: rationale and therapeutic options. Wounds-A Compendium of Clinical Research and Practice, 14(7), 2E-U1. 